\title{
Voltage Profile Enhancement and Losses Reduction at Future Expansion of Transmission power Systems
}

\author{
Baqer Turki Al-lamey \\ Technical Institute of Nasiriyah \\ Foundation of Technical Education
}

\begin{abstract}
The current paper presents flexible and feasible method for enhance the voltage profile in some buses and reduction of the losses in overall transmission power system if the power system subjected to an additional resultant loads in future or current increasing of loads at one or more buses in that power system. The proposed method include estimating the injected MVARs which are required to avert voltage collapse as well as reduction the real power losses. This method is tested by computer simulation implemented on IEEE 30-bus, 41-line transmission power system using MATLAB ToolBox (Ver. 7.5) based on fast decoupled load flow analysis and satisfactory results are obtained.
\end{abstract}




\section{Introduction:}

Power quality is one of the most important topics from electrical energy consumer's point of view. Among different power quality factors such as voltage harmonics, voltage imbalance, voltage sag, voltage swell and flicker, it is possible to say that voltage magnitude regulation and losses reduction is the most common problems.

The power produced in any power station can be carried on the line to long distances using transformers. When the electrical power is being used by loads, active and reactive powers can be drawn, depending on the type of loads. Even when the load is resistive, some reactive power is still needed for the long transmission lines, which act sometimes as inductive loads [1], in this respect an efficient control technique is needed. The main objective function of reactive power control is to: [2]

- Improve the voltage profiles.

- Minimize the system losses.

According to Dilek in [3] , the minimum and maximum values of bus voltages must be maintain at the pre-specified allowable bus voltages $(1 \pm 5 \%)$ per-unit value.

Several methods have been employed to avoid the voltage collapse and losses reduction in transmission systems. Some of these methods use sensitivity analysis for enhance the voltage profile and reduce the total power losses [4-7], and the other methods use artificial intelligent (AI) approaches [8-10] to identify the size and candidate nodes which are required to inject reactive power on it.

This research presents a method include increasing the load in some buses until voltage violent is occurs, then calculating the required capacitor size that must be installed in that bus with variant load levels which are computed by the same procedure.

\section{Classical Compensation methods:}

In the analysis of transmission networks for design and operational purposes it is often necessary to include a more rigorous line representation particularly where longer transmission distances are involved. This may include lumped parameters (series reactance, series resistance and shunt capacitor) or where a more exact representation is required these parameters can be distributed.

Referring to the simplified model of the uncompensated system of Figure (1) the voltage at the mid point of the line is taken to be VM, the real power P, exported along the line is given as:[11]

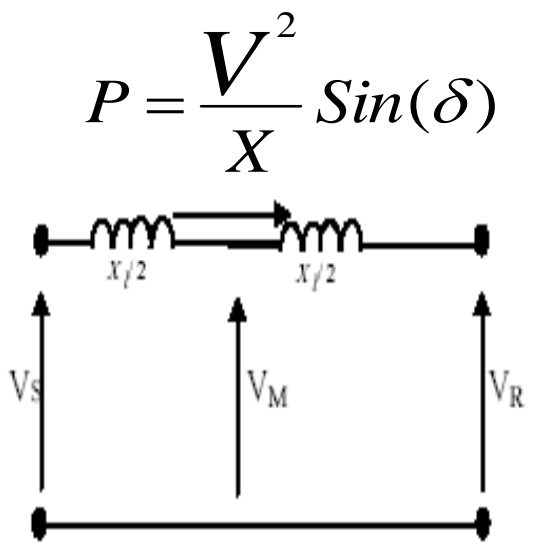

Figure (1): Simple Power system Model

Classical compensation can be summarized as:- [12] 


\section{Series Compensation:}

Series capacitors reduce the total reactance of the transmission line, which is often the main reason for their application. This improves power system stability, reduces reactive power losses and improves voltage regulation of the transmission line. The power flow along the transmission line is directly proportional to the difference of the phase angle and inversely proportional to the magnitude of the reactance. This concept can be demonstrated by using simple two bus lossless system as shown in Figure (2) with bus-1 having a voltage magnitude $V_{1}$ at an angle $\delta_{1}$ and bus-2 having a voltage $V_{2}$ at an angle $\delta_{2} \cdot[11]$

$$
P=\frac{\left|V_{1}\right|\left|V_{2}\right|}{X_{1}-X_{2}} \operatorname{Sin}\left(\delta_{1}-\delta_{2}\right)
$$

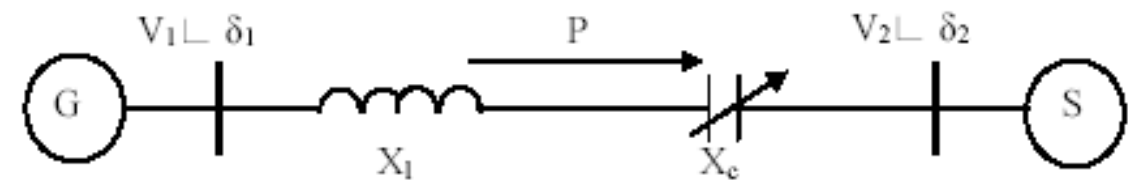

Figure (2): Simple two bus lossless system

The reactance associated with the line limits the power transfer through the system. However, the value of $X_{1}$ could be decreased, to increase the power transfer, by adding series capacitances as seen in equation 2. One of the important results of series capacitor application is the reduction of the reactive power losses in the system especially in the compensated line.

\section{Shunt Compensation:}

Figure (3) shows the arrangement of the ideal mid-point shunt compensator which maintains a voltage, mid-point voltage $(\mathrm{VM})$ equal to the bus bar voltage such that sending voltage $(|\mathrm{VS}|)=$ receiving voltage $(|\mathbf{V R}|)=$ mid-point voltage $(|\mathrm{VM}|)$. It can be seen that the compensator does not consume real power since the compensator voltage; VM and its current IM are in quadrature. Clearly, the power, power transferred from sending end (S) to the mid-point is equal to the power transferred from the midpoint to receiving $(\mathrm{R})$ end, and is given by:[11]

$$
P=\frac{V^{2}}{X / 2} \operatorname{Sin}(\delta / 2)=\frac{2 V^{2}}{X} \operatorname{Sin}(\delta / 2)
$$
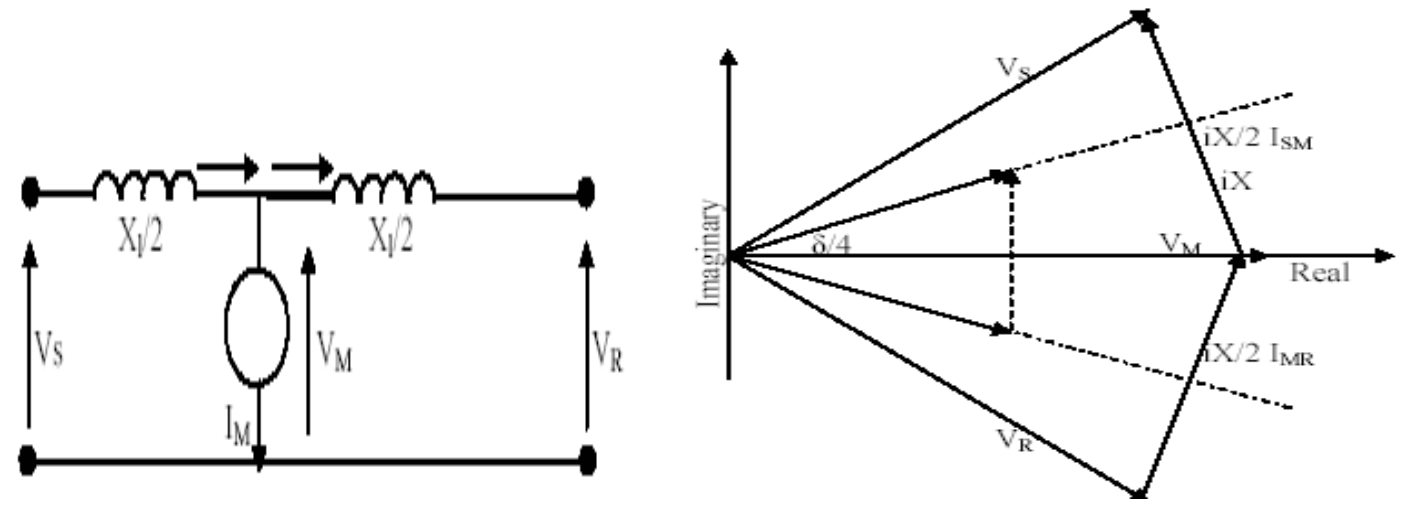

Figure (3):. Simple model with mid-point shunt Compensation 
The reactive power generated by the compensator $Q_{P}$ is given by:

$$
\begin{aligned}
& Q_{P}=I_{M} V_{M} \\
& Q_{P}=\frac{4 V^{2}}{X}\left(1-\operatorname{Cos}\left(\frac{\delta}{2}\right)\right)
\end{aligned}
$$

\section{Fast Decoupled Load-Flow Methods:-}

A power flow study will provide extensive information about the system's state, weaknesses, and possible expansion opportunities. The most important information given by the power flow is the voltage and phase angle at each node. Real and reactive power may also be obtained, though the accuracy of the output depends on the system stance. Power flow systems today are simulated through computer software that can generate an output in a manner of minutes. These commercial and private software programs vary depending on the amount of buses and components allowed within a project. Power flow solutions base themselves on system constraints and assumptions.[13]

In power-Flow problem there are a number of nonlinear relation- ships between voltage and current at each bus which must be solved for all voltages and currents such that these nonlinear relationships are met. The complexity of obtaining a formal solution for Power-Flow in power system arises because of differences in the type of data specified for the different type of buses. Although the formulation of sufficient equations to match the number of unknown state variables is not difficult, the closed form of solution is not practical. [14]

There are many methods which provide digital solution to Power-Flow solutions that follow an iterative process, but the most sufficient method is the Fast-Decoupled method. This method offers a uniquely attractive combination of advantages over established methods, including Gauss Seidel and Newton-Raphson, in terms of computational speed, reliability, simplicity and storage for power flow solutions [15]. The program which was used in this study applies the Fast Decoupled method in MATLAB Language and the flow chart of this program is shown in Figure (4). 


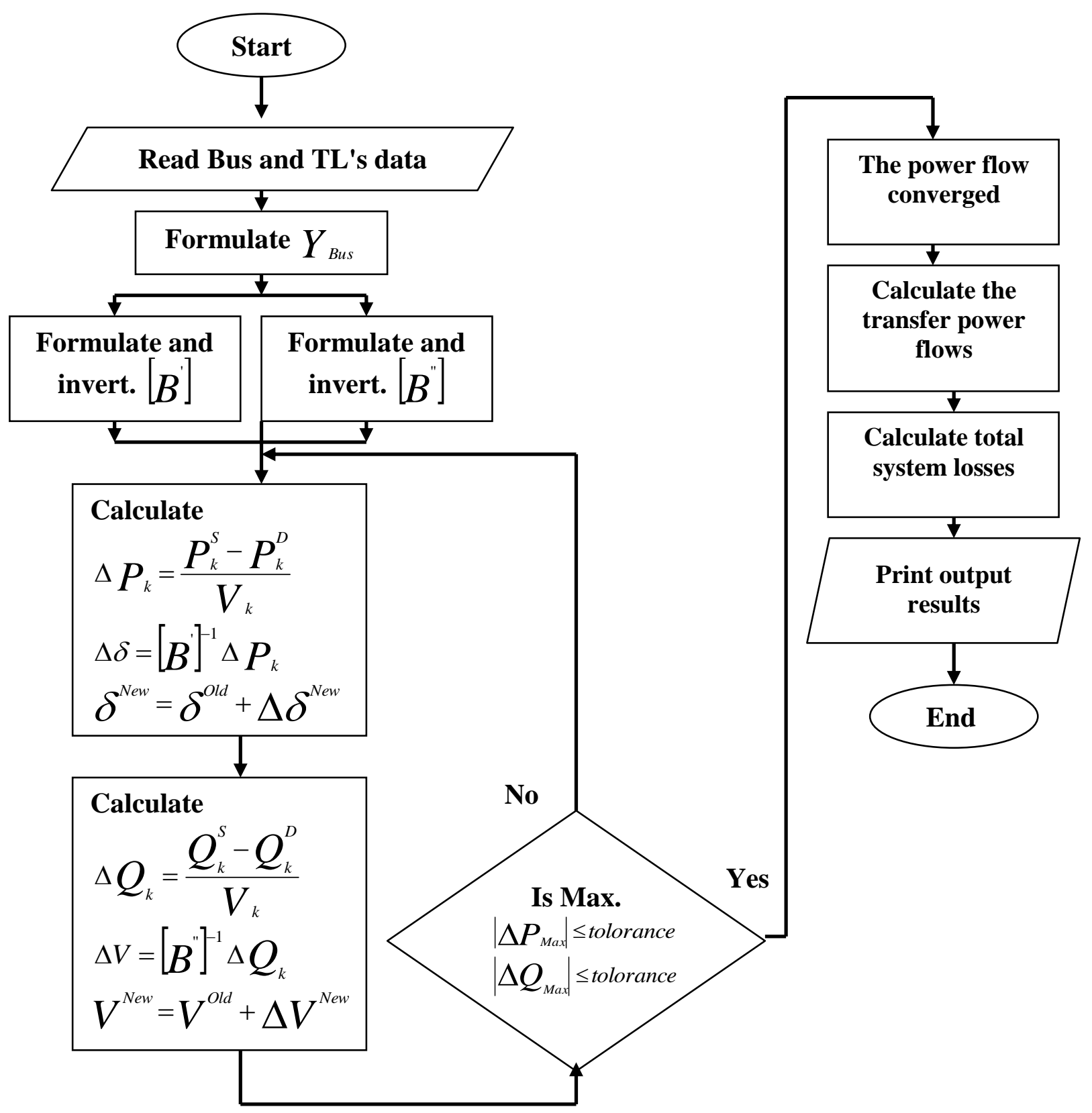

Figure (4): Flow chart for a fast decoupled power flow program

\section{Problem formulation and Proposed Method::}

The power system model is described by the power flow equations:- [16]

$$
\begin{gathered}
P_{i}=\left|V_{i}\right|^{2} G_{i i}+\sum_{\substack{n=1 \\
n \neq i}}^{N}\left|V_{i} V_{n} Y_{i n}\right| \operatorname{Cos}\left(\theta_{i n}+\delta_{n}-\delta_{i}\right) \\
Q_{i}=-\left|V_{i}\right|^{2} B_{i i}-\sum_{\substack{n=1 \\
n \neq i}}^{N}\left|V_{i} V_{n} Y_{i n}\right| \operatorname{Sin}\left(\theta_{i n}+\delta_{n}-\delta_{i}\right)
\end{gathered}
$$

Where: $G_{i i}$ and $B_{i i}$ are self conductance and susceptance of bus i. 
$G_{\text {in }}$ and $B_{\text {in }}$ are conductance and susceptance from bus i to bus n.

$P_{i}$ and $Q_{i}$ are active and reactive power injection at bus i.

$V_{i}$ and $\delta_{i}$ are voltage magnitude and angle at bus i.

$Y_{\text {in }}$ is admittance of line from bus i to bus $\mathrm{n}$.

The real power losses are given as:-[16]

$$
P_{\text {Losses }}=\sum_{i=1}^{N} G_{i}\left(V_{i}^{2}+V_{j}^{2}-2 V_{i} V_{j} \operatorname{Cos}\left(\delta_{i}-\delta_{j}\right)\right)
$$

Due to future expansion or increasing in current loads transmission power system may be subjected to voltage collapse and to avoid this situation an additional reactive power must injected. In the following the steps of algorithm that is used to avoid the voltage collapse:-

Step-1:- Perform the Load-Flow program to calculate overall real power losses in power system.

Step-2:- Increased the load in some specified buses by fixed amount according to expectant increase of load in future.

Step-2:- Perform the Load-Flow program again to know if there is voltage collapse in specified buses.

Step-4:- If there is a voltage collapse in system buses, select an appropriate value of reactive power to injected in one of these buses that required to avoid the voltage collapse, then perform the Load-Flow program to ensure correct voltage profile and to calculate the reduction in overall real power losses.

Step-5:- Select another bus from the pre-specified buses and repeat steps (2-4).

Step-6:- Repeat steps (2-5) for all specified buses.

\section{Test Power System:}

The transmission power system under consideration represents a standard IEEE 30bus, 41-line consist of one slack bus (bus-1), five voltage controlled buses (buses of 26,27,28,29 and 30) and twenty four load bus (from bus-2 to bus-25), the data of transmission lines and buses of transmission power system are tabulated in Table (1). 
Table (1): Transmission lines and buses data of test system

\begin{tabular}{|c|c|c|c|c|c|c|c|c|c|c|}
\hline \multicolumn{4}{|c|}{ Transmission lines data } & \multicolumn{7}{|c|}{ Buses data } \\
\hline $\begin{array}{l}\text { From } \\
\text { bus }\end{array}$ & $\begin{array}{l}\text { To } \\
\text { bus }\end{array}$ & $\begin{array}{l}\text { R } \\
(\mathbf{P . U})\end{array}$ & $\begin{array}{l}X \\
(\mathbf{P . U})\end{array}$ & $\begin{array}{l}\text { Bus } \\
\text { No. }\end{array}$ & $\begin{array}{c}\mathbf{V} \\
(\mathbf{P . U})\end{array}$ & $\underset{\text { rad. }}{\delta}$ & $\begin{array}{c}P_{G} \\
\text { MW }\end{array}$ & $\begin{array}{c}Q_{G} \\
\mathbf{M W}\end{array}$ & $\underset{\text { MW }}{P_{L}}$ & $\underset{\mathbf{M W}}{Q_{L}}$ \\
\hline 1 & 26 & 0.0192 & 0.0575 & 1 & 1.050 & 0.00 & 0.00 & $\mathbf{0 . 0 0}$ & 0.00 & 0.00 \\
\hline 1 & 3 & 0.0452 & 0.1852 & 2 & 1.000 & 0.00 & 0.00 & 0.00 & 3.50 & 2.30 \\
\hline 26 & 4 & 0.0570 & 0.1737 & 3 & 1.000 & 0.00 & 0.00 & 0.00 & 2.40 & 1.20 \\
\hline 3 & 4 & 0.0132 & 0.0379 & 4 & 1.000 & 0.00 & 0.00 & 0.00 & 7.60 & 1.60 \\
\hline 26 & 27 & 0.0472 & 0.1983 & 5 & 1.000 & 0.00 & 0.00 & 0.00 & $\mathbf{0 . 0 0}$ & 0.00 \\
\hline 26 & 6 & 0.0581 & 0.1763 & 6 & 1.000 & 0.00 & 0.00 & 0.00 & 0.00 & $\mathbf{0 . 0 0}$ \\
\hline 4 & 6 & 0.0119 & 0.0414 & 7 & 1.000 & 0.00 & 0.00 & 0.00 & 22.8 & 10.9 \\
\hline 27 & 7 & 0.0460 & 0.1160 & 8 & 1.000 & 0.00 & 0.00 & 0.00 & 0.00 & 0.00 \\
\hline 6 & 7 & 0.0267 & 0.0820 & 9 & 1.000 & 0.00 & 0.00 & 0.00 & 0.00 & 0.00 \\
\hline 6 & 28 & 0.0120 & 0.0420 & 10 & 1.000 & 0.00 & 0.00 & 0.00 & 5.80 & 2.00 \\
\hline 6 & 9 & 0.0000 & 0.2080 & 11 & 1.000 & 0.00 & 0.00 & 0.00 & 2.40 & 0.90 \\
\hline 6 & 10 & 0.0000 & 0.5560 & 12 & 1.000 & 0.00 & 0.00 & 0.00 & 11.2 & 7.50 \\
\hline 9 & 29 & 0.0000 & 0.2080 & 13 & 1.000 & 0.00 & 0.00 & 0.00 & 10.6 & 1.90 \\
\hline 9 & 10 & 0.0000 & 0.1100 & 14 & 1.000 & 0.00 & 0.00 & 0.00 & 6.20 & 1.60 \\
\hline 4 & 12 & 0.0000 & 0.2560 & 15 & 1.000 & 0.00 & 0.00 & 0.00 & 8.20 & 2.50 \\
\hline 12 & 30 & 0.0000 & 0.1400 & 16 & 1.000 & $\begin{array}{c}0.00 \\
\end{array}$ & $\begin{array}{c}0.00 \\
\end{array}$ & 0.00 & 3.50 & 1.80 \\
\hline 12 & 14 & 0.1231 & 0.2559 & 17 & 1.000 & 0.00 & 0.00 & 0.00 & 9.00 & 5.80 \\
\hline 12 & 15 & 0.0662 & 0.1304 & 18 & 1.000 & 0.00 & 0.00 & 0.00 & 3.20 & 0.90 \\
\hline 12 & 16 & 0.0945 & 0.1987 & 19 & 1.000 & 0.00 & 0.00 & 0.00 & 9.50 & 3.40 \\
\hline 14 & 15 & 0.2210 & 0.1997 & 20 & 1.000 & 0.00 & 0.00 & 0.00 & 2.20 & 0.70 \\
\hline 16 & 17 & 0.0824 & 0.1932 & 21 & 1.000 & 0.00 & 0.00 & 0.00 & $\mathbf{1 7 . 5}$ & 11.2 \\
\hline 15 & 18 & $\mathbf{0 . 1 0 7 0}$ & 0.2185 & 22 & 1.000 & 0.00 & 0.00 & 0.00 & 0.00 & 0.00 \\
\hline 18 & 19 & 0.0639 & 0.1292 & 23 & 1.000 & 0.00 & 0.00 & 0.00 & 3.20 & 1.60 \\
\hline 19 & 20 & 0.0340 & 0.0680 & 24 & 1.000 & 0.00 & 0.00 & 0.00 & 8.70 & 6.70 \\
\hline 10 & 20 & 0.0936 & 0.2090 & 25 & 1.000 & $\begin{array}{c}0.00 \\
\end{array}$ & 0.00 & 0.00 & 0.00 & 0.00 \\
\hline 10 & 17 & 0.0324 & 0.0845 & 26 & 1.045 & 0.00 & 80.0 & $\begin{array}{l}0.00 \\
\end{array}$ & 21.7 & 12.7 \\
\hline 10 & 21 & 0.0348 & 0.0749 & 27 & 1.010 & 0.00 & 50.0 & 0.00 & 94.2 & 19.0 \\
\hline 10 & 22 & 0.0727 & 0.1499 & 28 & 1.010 & 0.00 & 20.0 & 0.00 & 30.0 & 30.0 \\
\hline 21 & 22 & 0.0116 & 0.0236 & 29 & 1.050 & 0.00 & 20.0 & 0.00 & 0.00 & 0.00 \\
\hline 15 & 23 & 0.1000 & 0.2020 & 30 & 1.050 & 0.00 & 20.0 & 0.00 & 0.00 & 0.00 \\
\hline 22 & 24 & 0.1150 & 0.1790 & & & & & & & \\
\hline 23 & 24 & 0.1320 & 0.2700 & & & & & & & \\
\hline 24 & 25 & 0.1885 & 0.3292 & & & & & & & \\
\hline 25 & 2 & 0.2544 & 0.3800 & & & & & & & \\
\hline 25 & 5 & 0.1093 & 0.2087 & & & & & & & \\
\hline 8 & 5 & 0.0000 & 0.3960 & & & & & & & \\
\hline 5 & 11 & 0.2198 & 0.4153 & & & & & & & \\
\hline 5 & 13 & 0.3202 & 0.6027 & & & & & & & \\
\hline 11 & 13 & 0.2399 & 0.4533 & & & & & & & \\
\hline 28 & 8 & 0.6360 & 0.2000 & & & & & & & \\
\hline 6 & 8 & 0.0169 & 0.0599 & & & & & & & \\
\hline
\end{tabular}




\section{Simulation results:}

Future expansion considered at buses 2 and 13, the expectant real load power varied in bus-2 from $5 \mathrm{MW}$ to $12 \mathrm{MW}$ in steps of $1 \mathrm{MW}$ and from $15 \mathrm{MW}$ to $22 \mathrm{MW}$ in steps of $1 \mathrm{MW}$ in bus-13. The future reactive power in these buses remains constant at either 10 Mvar or 20 Mvar. The required reactive powers which are injected in the specified buses in order to remain the buses voltages at its pre-specified accepted values with the resultant real power losses reduction before and after reactive power injection are tabulated in Tables (2) and (3). Table (2) show the simulation results in case of future reactive load in specified buses equal to (10Mvar) and the simulation results in case of the future reactive load equal to (20Mvar) are tabulated in Table (3).

Figure (5) show the losses power in overall transmission power system before and after reactive power injection in that buses, while Figure (6) show the voltage profile of specified buses before and after injection.

\section{Conclusion:}

A simplified approach to estimate the appropriate required quantity of reactive power injected in some specified buses to enhance voltage profile and reduce the real power losses in transmission power systems has been presented in this study. The voltage collapse occurs in power systems as a result of the loads increasing or from future expansion, the proposed method manipulate this situation to enhance the power system performance.

The current study illustrated that the improving in voltage profile lead to significant increase in loadability of power systems, for this reason the current study represents a flexible and feasible tool to electrical engineers in planning and implementing stages of transmission power systems design.

$$
\text { Table (2): Simulation results when the future } Q_{L O A D}=10 \mathrm{Mvar}
$$

\begin{tabular}{|c|c|c|c|c|c|c|}
\hline $\begin{array}{l}\text { Bus } \\
\text { No. }\end{array}$ & $\begin{array}{c}\text { Future } \\
P_{L O A D}^{(\mathbf{M W})}\end{array}$ & $\begin{array}{l}\text { Required } \\
\text { MVAR } \\
\text { Injection }\end{array}$ & $\begin{array}{c}|V| \\
\text { Before } \\
\text { enhance } \\
\text { (P.U) }\end{array}$ & $\begin{array}{c}|V| \\
\text { After } \\
\text { enhance } \\
\text { (P.U) }\end{array}$ & $\begin{array}{c}P_{\text {Losses }} \\
\text { Before } \\
\text { enhance } \\
\text { (MW) }\end{array}$ & $\begin{array}{c}P_{\text {Losses }} \\
\text { After } \\
\text { enhance } \\
(\mathbf{M W})\end{array}$ \\
\hline \multirow{8}{*}{$\begin{array}{c}\text { Bus } \\
\text { No.-2 }\end{array}$} & 5 & 9.2 & 0.8738 & 0.9501 & 6.4513 & 5.7266 \\
\hline & 6 & 9.8 & 0.8688 & 0.9501 & 6.5962 & 5.8384 \\
\hline & 7 & 10.4 & 0.8636 & 0.9501 & 6.7545 & 5.9628 \\
\hline & 8 & 11 & 0.8584 & 0.9500 & 6.9266 & 6.1000 \\
\hline & 9 & 11.65 & 0.8529 & 0.9501 & 7.1133 & 6.2495 \\
\hline & 10 & 12.28 & 0.8473 & 0.9500 & 7.3151 & 6.4124 \\
\hline & 11 & 12.928 & 0.8415 & 0.9500 & $\mathbf{7 . 5 3 3 0}$ & 6.5886 \\
\hline & 12 & 13.62 & 0.8355 & 0.9501 & 7.7676 & 6.7784 \\
\hline \multirow{8}{*}{$\begin{array}{c}\text { Bus } \\
\text { No.-13 }\end{array}$} & 15 & 12 & 0.8585 & 0.9532 & 6.8514 & 6.1599 \\
\hline & 16 & 12.5 & 0.8540 & 0.9530 & 7.0476 & 6.3174 \\
\hline & 17 & 12.8 & 0.8493 & 0.9512 & 7.2555 & 6.4852 \\
\hline & 18 & 13.2 & 0.8445 & 0.9502 & 7.4756 & 6.6601 \\
\hline & 19 & 13.8 & 0.8395 & 0.9509 & 7.7084 & 6.8417 \\
\hline & 20 & 14.5 & 0.8343 & 0.9513 & 7.9547 & 7.0317 \\
\hline & 21 & 15 & 0.8290 & 0.9506 & 8.2152 & 7.2317 \\
\hline & 22 & 15.6 & 0.8234 & 0.9506 & 8.4906 & 7.4402 \\
\hline
\end{tabular}



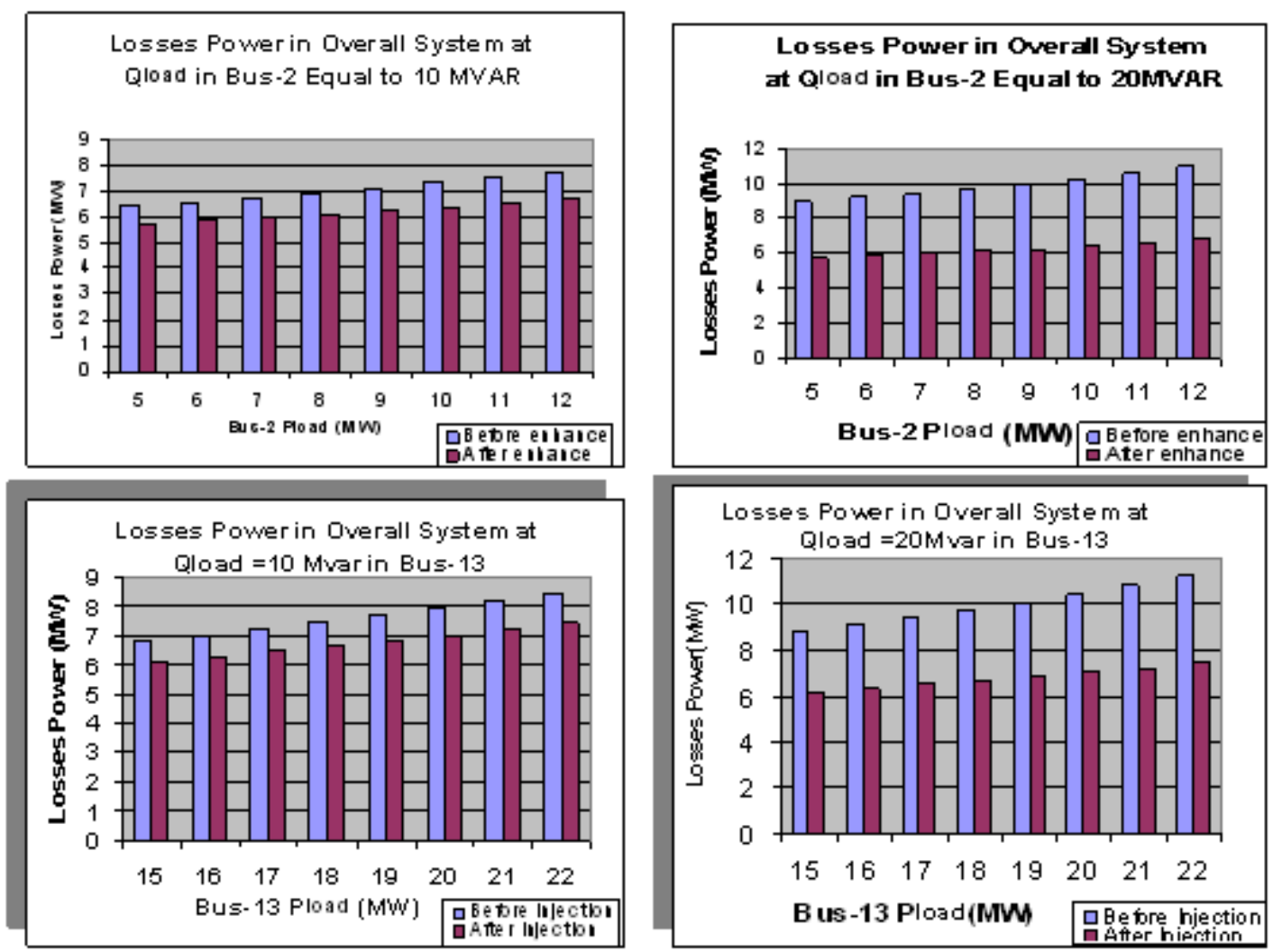

Figure (5) Losses Power in Overall Transmission Power System Table

(3): Simulation results when the future $Q_{L O A D} 20 \mathrm{Mvar}$

\begin{tabular}{|c|c|c|c|c|c|c|}
\hline $\begin{array}{l}\text { Bus } \\
\text { No. }\end{array}$ & $\begin{array}{c}\text { Future } \\
P_{L O A D}^{(\mathbf{M W})}\end{array}$ & $\begin{array}{c}\text { Required } \\
\text { VAR } \\
\text { Injection }\end{array}$ & $\begin{array}{c}|V| \\
\text { Before } \\
\text { enhance } \\
\text { (P.U) }\end{array}$ & $\begin{array}{c}|V| \\
\text { After } \\
\text { enhance } \\
\text { (P.U) }\end{array}$ & $\begin{array}{c}P_{\text {Losses }} \\
\text { Before } \\
\text { enhance } \\
\text { (MW) }\end{array}$ & $\begin{array}{c}P_{\text {Losses }} \\
\text { After } \\
\text { enhance } \\
(\mathbf{M W})\end{array}$ \\
\hline \multirow{8}{*}{$\begin{array}{c}\text { Bus } \\
\text { No.-2 }\end{array}$} & 5 & 19.200 & 0.7650 & 0.9501 & 8.9547 & 5.7266 \\
\hline & 6 & 19.800 & $\mathbf{0 . 7 5 8 7}$ & 0.9501 & 9.1640 & 5.8384 \\
\hline & 7 & 20.380 & 0.7521 & 0.9500 & 9.3948 & 5.9632 \\
\hline & 8 & 21.000 & 0.7452 & 0.9500 & 9.9485 & 6.1000 \\
\hline & 9 & 21.680 & 0.7380 & 0.9504 & 9.9270 & 6.2492 \\
\hline & 10 & 22.400 & 0.7304 & 0.9509 & 10.2324 & 6.4118 \\
\hline & 11 & 23.000 & 0.7224 & 0.9505 & 10.5672 & 6.5885 \\
\hline & 12 & 23.800 & 0.7138 & 0.9514 & $\mathbf{1 0 . 9 4 3 5}$ & 6.7790 \\
\hline \multirow{8}{*}{$\begin{array}{c}\text { Bus } \\
\text { No.- } \\
13\end{array}$} & 15 & 21.800 & 0.7534 & 0.9518 & 8.8446 & 6.1623 \\
\hline & 16 & 22.400 & 0.7473 & 0.9523 & 9.1187 & 6.3185 \\
\hline & 17 & 22.800 & 0.7409 & 0.9512 & 9.4128 & 6.4852 \\
\hline & 18 & 23.500 & 0.7340 & 0.9523 & 9.7349 & 6.6576 \\
\hline & 19 & 24.000 & 0.7269 & 0.9518 & 10.0768 & 6.8403 \\
\hline & 20 & 24.400 & 0.7193 & 0.9506 & 10.4457 & 7.0322 \\
\hline & 21 & 25.000 & 0.7113 & 0.9506 & 108449 & 7.2317 \\
\hline & 22 & 25.600 & 0.7028 & 0.9506 & 11.2782 & 7.4402 \\
\hline
\end{tabular}



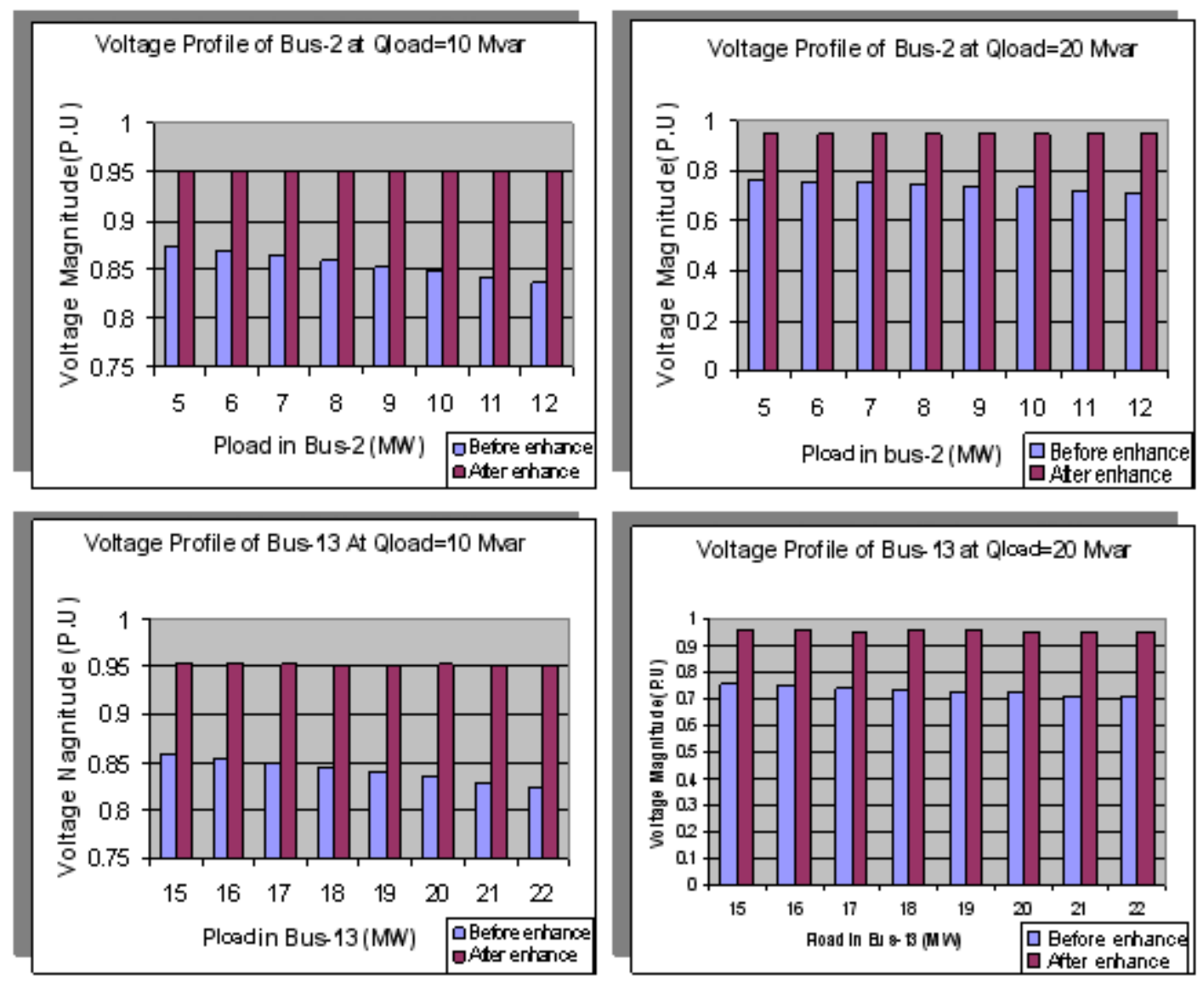

Figure (6): Voltage Profile of Specified Buses

\section{References:}

1- I. Colak, R. Bayindir and I. Sefa, 2004, "Experimental study on reactive power compensation using a fuzzy logic controlled synchronous motor", Energy Conversion and Management 45 .

2- Gerald, B. Sheble, L., 1987, "EEE Tutorial Course, reactive Power: Basics problem and solution".

3- Dilek ,Murat ,2001," Integrated Design of Electrical Distribution Systems: Phase Balancing and Phase Prediction Case Studies", Ph.D. Thesis, Virginia Polytechnic Institute and State University.

4- M. Rodr yguez Montan and et..al," Voltage Sensitivity Based Technique for optimal Placement of switched Capacitors", 15th PSCC, Liege, 22-26 August 2005.

5- Venkatesh, B., H. B. Gooi and A. Arunagiri,2003,"Unified OPF Method for Maximizing Voltage Stability Margin using Successive Fuzzy LP". Int. J. Electric Power System.

6- Venkatesh, B., Rakesh Ranjan and A. Arunagiri,2003,"On-line ANN Memory model based method for Unified OPF and Voltage Stability Margin Maximization", Accepted for publication in the Int. J. Electric Power Components and System, USA.

7- Venkatesh, B., G. Sadasivam and M. Abdullah Khan.,2000, "A new optimal reactive power scheduling method for loss minimization and voltage stability margin maximization using successive multi-objective fuzzy LP technique", IEEE Transactions on Power Systems, 15.

8- M. Tarafdar Haque, and S. Najafi," Application of Neuro-Fuzzy Dynamic Programming to Improve the Reactive Power and Voltage Profile of a Distribution Substation", Transaction on Engineering, Computing and Technology, V6 June, 2005, ISSN 1305-5313. 
9- Houssem BEN ARIBIA and Hsan HADJ ABDALLAH," Multi Objectives Reactive Dispatch Optimization of an Electrical Network", Leonardo Journal of Sciences Issue 10, JanuaryJune 2007.

10- Prasad, P.V. , Sivanagaraju, S. and Sreenivasulu, N.," A Fuzzy Genetic Algorithm for Optimal Capacitor Placement in Radial Distribution System", ARPN Journal of Engineering and Applied Sciences, 2(3), JUNE 2007 ISSN.

11- Belkacem MAHDAD, Tarek BOUKTIR, and Kamel SRAIRI, "Dynamic Compensation of the Reactive Energy using a Fuzzy Controller", Leonardo Electronic Journal of Practices and Technologies ,ISSN 1583-1078 ,Issue 7, July-December 2005.

12- Miller T. J. E., 1984,"Reactive Power Control in Electric System", John Wiley \& Sons, New York.

13- Pierre Alexandre Bohême, 2006," Simulation of Power System Response to Reactive Power Compensation", M.Sc.Thesis ,University of Tennessee, Knoxville.

14- Shant K. Avakian and et..al," The Application of Agent Technology on the power Flow of Iraqi Super Grid Network", American Journal of Applied Sciences 3(12):2174-2177,2006.

15- Anwer A., 2005,"Implementation of Geographic Information System (GIS) in Transient Stability Assessment", M.Sc.Thesis,University of Technology,Electrical and Electronic Department,Baghdad, Iraq.

16- Grainger, John. J and Stevenson, D. William .Jr, 2003,"Power System analysis”, Neperdazan, Iran.

$$
\begin{aligned}
& \text { الخلاصة } \\
& \text { البحث الحالي يقدم طريقة مرنة وعلية لتحسين الفولتية في بعض عموميات التوصــيل الكهربائيــة التـي }
\end{aligned}
$$

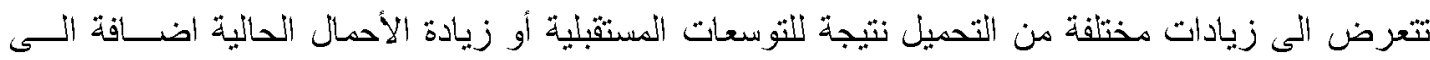

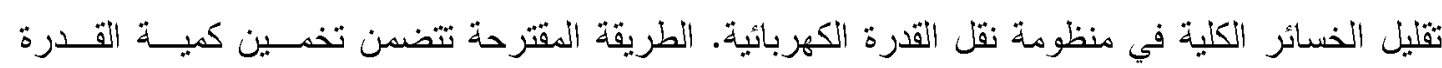

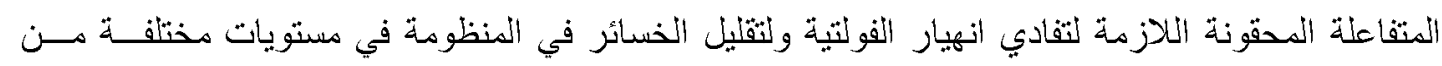

$$
\begin{aligned}
& \text { التحميل, هذه الدر اسة أختبرت على منظومة نقل كهربائية مؤلفة من (30) عمومي و (41) خط نقـلـ وتهـــ } \\
& \text { استخلاص النتائج التي بينت فاعلية الطريقة المفترحة في حل مشكلة انهيار الفولت وزيادة الخسائر . } \\
& \text { بر امج المحاكاة المقترحة بنيت بأستخدام MATLAB Tool-Box (Ver. 7.5 بالأعتماد على سي }
\end{aligned}
$$

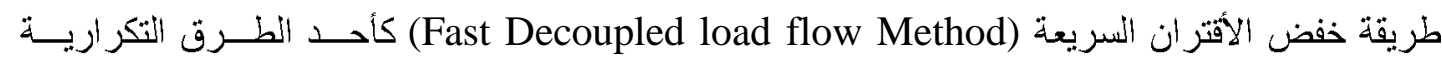

$$
\begin{aligned}
& \text { المستخدمة في تحليل مشكلة تدفق الحمل في منظومة القدرة الكهربائية. }
\end{aligned}
$$

